\title{
PERGESERAN BAHASA SEBAGAI DAMPAK SIKAP BAHASA
}

\author{
oleh Dwiyani Pratiwi \\ FBS Universitas Negeri Yogyakarta
}

\begin{abstract}
Language contact in a bilingual or multilingual community can cause impacts on the development of the languages used by the community concerned. One of the impacts is language shift. Factors that are conducive to language shift are varied. One of these factors is language attitude. This article discusses a further impact that language shift itself can in turn cause, i.e., language death, its process, and the efforts made by individuals, social groups, and the government in authority to maintain the existence of a language, which implies language maintenance.
\end{abstract}

Keywords: language shift, language maintenance

\section{A. PENDAHULUAN}

Sejalan dengan berkembangnya berbagai bahasa di dunia, tidak aneh lagi jika seseorang atau suatu komunitas mampu menggunakan dua bahasa (bilingualisme) dan lebih dari dua bahasa (multilingualisme). Di negara-negara yang hanya menggunakan satu bahasa resmi (tidak ada bahasa daerah) seperti di Amerika Serikat sekitar 7\% penduduknya menggunakan bahasa selain bahasa Inggris, di Jepang beberapa kelompok orang Cina berbahasa Cina, dan di beberapa negara di Afrika lebih dari $90 \%$ penduduknya menggunakan lebih dari satu bahasa (Crystal, 1987:360).

Menurut Wardhaugh (1992) bilingualisme dan multilingualisme disebabkan oleh beberapa faktor, antara lain karena perpindahan penduduk (oleh para imigran), pengunjung suatu masyarakat, perkawinan antara dua orang yang menggunakan bahasa/kode yang berbeda, perdagangan, pendidikan, dan karena berhubungan dengan dunia internasional. Selain itu faktor-faktor seperti status, prestis, dan kesukaan menjadi penyebab munculnya bilingualisme dan multilingualisme ini. Misalnya di Indonesia, penggunaan Bahasa Inggris semakin meluas karena masyarakat semakin sadar bahwa dengan menguasai bahasa asing, terutama bahasa Inggris (untuk saat ini) maka masyarakat akan dianggap berkualitas dan akan berdampak pada pekerjaan yang akan mereka peroleh.

Kontak bahasa dalam masyarakat bilingual atau multilingual dapat memberikan dampak terhadap perkembangan bahasabahasa yang digunakan dalam masyarakat tersebut. Dampak-dampak tersebut antara lain terjadi interferensi, integrasi, perubahan bahasa (language change), pergeseran bahasa (language shift), dan sebagainya. Selain itu sikap bahasa sangat menentukan terjadinya perubahan bahasa.

Menjadi kekhawatiran banyak pihak, terutama negara yang di dalammya berkembang banyak bahasa, akan terjadi pergeseran bahasa (language shift). Dampak yang lebih jauh lagi akan terjadi kepunahan bahasa (language death) seperti yang terjadi pada bahasa Celtic, bahasa Mapia di Irian Jaya. Hanya ada satu penutur bahasa Mapia yang masih hidup dan sudah sangat tua. Bahasa Hukumania di Maluku juga hanya tinggal satu penuturnya yang sudah berusia delapan puluh tahun (pada tahun 1989). Kematian bahasa tidak hanya berdampak tidak adanya penutur bahasa tersebut, tetapi juga memberikan 
beberapa dampak yang lain, seperti hilangnya data tentang bahasa tersebut dan budaya suatu masyarakat. Oleh karena itu untuk menghindari terjadinya pergeseran bahasa, bahkan kepunahan bahasa perlu mencari penyebab munculnya pergeseran bahasa, terutama berkaitan dengan sikap bahasa. Paper ini bertujuan mengetahui sebab-sebab terjadinya pergeseran bahasa, dampak sikap bahasa oleh masyarakat penuturnya dan pemerintah yang berkuasa di dalam masyarakat terhadap pergeseran bahasa, dan upaya-upaya apa yang bisa ditempuh untuk mempertahankan kelangsungan hidup suatu bahasa (language maintenance).

\section{B. SIKAPBAHASA}

Sikap bahasa (langauge attitude) memiliki beberapa definisi. Menurut Anderson dalam Chaer dan Agustina (1995: 200) sikap bahasa adalah:

Tata keyakinan atau kognisi yang relatif berjangka panjang, sebagian mengenai bahasa, mengenai objek bahasa, yang memberikan kecenderungan kepada seseorang untuk bereaksi dengan cara tertentu yang disenanginya.

Sementara itu dalam Longman Dictionary of Applied Linguistics (Richard, Platt, dan Weber) disebutkan bahwa language attitude adalah:

The attitudes which speakers of different languages or language varieties have towards each other's language or their own language. Expressions of positive or negative feelings towards a language may reflect impressions of linguistic difficulty or simplicity, ease or difficulty of learning, degree of importance, elegance, social status, etc. Attitudes towards a language may also show what people feel about the speakers of that language.
Sementara itu, Edward (1994: 80-90) menyatakan bahwa sikap bahasa adalah sikap terhadap anggota sebuah komunitas bahasa dan sering dikaitkan dengan rasa yang kuat untuk melindungi sesuatu yang dimiliki oleh sekelompok orang.

Dari berbagai definisi di atas dapat dikatakan bahwa sikap bahasa (language attitude) adalah sikap yang diberikan atau ditunjukkan oleh seseorang atau sekelompok masyarakat bahasa, bisa positif atau negatif, terhadap suatu bahasa, penutur bahasa, dan halhal yang dimiliki oleh suatu kelompok bahasa, termasuk juga di dalamnya rasa/feeling terhadap berbagai hal terkait dengan bahasa tersebut.

Pergeseran bahasa (language shift) bisa diartikan sebagai:
A change ("shift") from the use of one language to the use of another language. This often occurs when people migrate to another country where the main language is different, ....... Language shift may be actively encouraged by official government policy, for example by restricting the number of language used as media of instruction. It may also occur because another language, usually the main language of the region, is needed for employement opportunities and wider communication (Richards, Platt, dan Weber, 1985: 159).

Holmes (1992: 64) memberikan definisi pergeseran bahasa (language shift) sebagai proses dimana bahasa yang digunakan seseorang pindah ke bahasa yang lain dalam lingkup kebahasaan dari suatu komunitas.

Jadi pergeseran bahasa merupakan perubahan pemakaian suatu bahasa ke bahasa yang lain yang terjadi secara bertahap pada suatu komunitas bahasa dikarenakan beberapa hal, seperti migrasi, kebijakan pemerintah, pekerjaan, dan sebagainya. 
C. P E R G E S E R A N B A H A S A (LANGUAGESHIFT)

Telah disebutkan di atas bahwa pergeseran bahasa (language shift) bisa terjadi pada masyarakat imigran atau sebaliknya terjadi pada masyarakat yang didatangi. Ketika suatu kelompok masyarakat yang bermigrasi ke suatu daerah atau kelompok masyarakat yang lain, mereka harus menyesuaikan dengan masyarakat setempat termasuk dalam menggunakan bahasa dalam berkomunikasi. Sedikit demi sedikit mereka mempelajari bahasa masyarakat setempat sehingga lamalama mereka menanggalkan bahasa mereka sendiri dan menggunakan secara utuh bahasa masyarakat setempat. Misalnya seseorang dari Palembang harus bekerja di Jogjakarta di mana dilingkungan tempat bekerja para rekan sekerja sebagian besar berasal dari Jogjakarta dan sekitarnya yang notabene berbicara bahasa Jawa (meskipun dengan dialek yang berbedabeda). Mau tidak mau ia harus belajar bahasa
Jawa agar dapat terlibat dalam komunikasi yang sama. Pertama-tama logat Palembang masih bercampur dengan logat Jawa dan kemudian setelah bertahun-tahun bekerja dan berkomunikasi dengan para pekerja lainnya tersebut bahasa Palembang atau logat Palembang akan mulai ditinggalkannya.

Contoh lainnya adalah yang sering terjadi di Amerika dimana banyak para imigran dari Meksiko, Spanyol, Amerika Latin masuk ke Amerika. Para anak-anak yang lahir dan besar di Amerika tidak tahu sama sekali dengan bahasa nenek moyang mereka/ bahasa ibunya. Fishman dalam Chaer dan Agustina (1995) menggambarkan pergeseran bahasa para imigran di Amerika. Keturunan ketiga atau keempat dari para imigran sudah tidak lagi mengenal bahasa ibunya (B-ib), dan terjadi monolingual bahasa Inggris (B-in). Secara sederhana pergeseran bahasa para imigran itu digambarkan sebagai berikut:

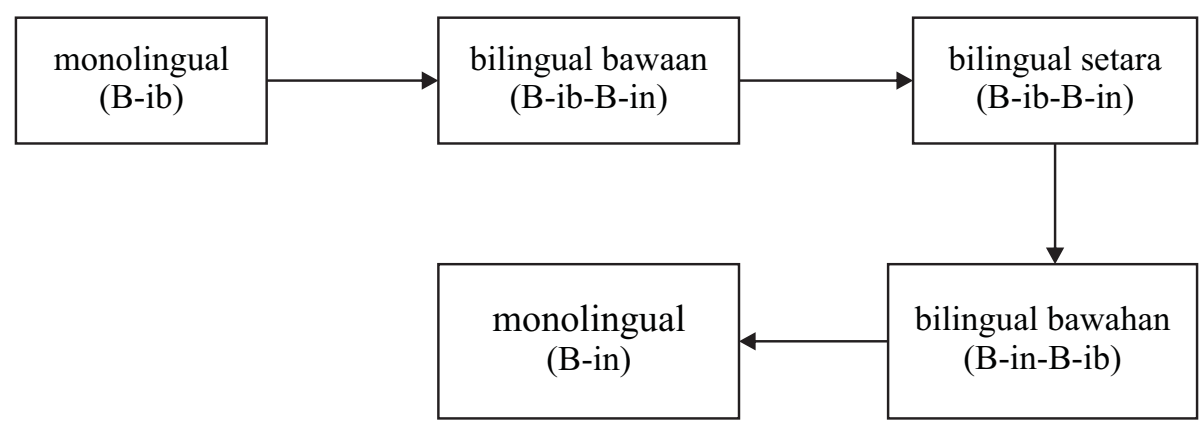

\section{Keterangan:}

1. Para imigran masih bermonolingual dengan bahasa ibunya;

2. Para imigran sudah menggunakan bahasa Inggris dan bahasa ibu, bahasa ibu lebih dominan;

3. Bilingualisme sudah setara, para imigran menggunakan bahasa Inggris dan bahasa ibu yang tingkat penguasaannya setara;

4. Para imigran lebih dominan menggunakan bahasa Inggris;

5. Para imigran menjadi monolingual bahasa Inggris dan melupakan bahasa ibunya. 
Pergeseran bahasa juga dapat disebabkan oleh perkawinan. Kecenderungan tersebut sekarang ini semakin sering muncul, terutama di daerah perkotaan, dimana di sana berkumpul orang-orang dari berbagai etnis atau negara. Para pasangan yang berasal dari etnis atau negara yang berbeda, yang masing-masing berbahasa ibunya dan saling tidak memahami, harus menggunakan salah satu bahasa yang bisa mereka pahami. Di Indonesia misalnya, bahasa Indonesia bisa digunakan oleh para pasangan yang berasal dari etnis yang berbeda dengan bahasa ibunya masing-masing, sehingga bahasa ibunya tidak digunakan lagi dalam berkomunikasi. Anak-anak mereka nantinya tidak mengenal bahasa ibu orang tua mereka dan menggunakan bahasa Indonesia untuk berkomunikasi. Jika hal itu berlangsung terusmenerus dalam waktu yang lama akan terjadi pergeseran bahasa bahkan kepunahan bahasa ibu.

Terdapat kasus menarik yang terjadi di Singapura. Bahasa yang diucapkan oleh pasangan suami-istri terhadap anak-anak atau cucu-cucu mereka berbeda dengan bahasa yang diucapkan oleh anak-anak atau cucu-cucu mereka kepada orang tua atau nenek/kakek mereka. Orang-orang Tamil berbicara kepada anak-anak/cucu-cucu mereka dengan bahasa Tamil, tetapi para anak/cucu menjawab dengan bahasa Inggris. Meskipun mereka paham dengan bahasa Tamil, mereka enggan berbicara bahasa Tamil dan lebih memilih bahasa Inggris untuk berkomunikasi. Hal ini terutama terjadi pada masyarakat Tamil yang memiliki pendidikan yang baik (well-educated Tamils). Sikap berbahasa mereka, yang memilih menggunakan bahasa Inggris untuk berkomunikasi, disebabkan oleh beberapa faktor, antara lain kebijakan pendidikan yang diterapkan di Singapura. Bahasa Tamil ditawarkan atau diberikan pada pendidikan sebelum jenjang Universitas. Dalam sistem pendidikan sekolah yang bermedium bahasa Inggris (English-medium school system) bahasa Tamil banyak digunakan pada level dasar (sekolah dasar) dan pada level yang lebih tinggi penggunaan bahasa Tamil mulai berkurang. Akibatnya mereka mulai meninggalkan bahasa
Tamil. Seorang ahli, Jeganathan, menyebutkan bahwa:

Tamil is taught as a second language for the Tamil pupils. Most of these pupils speak English with their friends and even at home with their Englisheducated parents. Only where there are grandparents who are not English educated might these pupils speak Tamil....

The Tamil language taught in schools, therefore, appears to be more for evaluation purposes......This has therefore led to a concern for accuracy work...(i.e.) accurate use of the language in the classroom (rather) than...outside the classroom. (Jaganathan dalam Schiffman, 1996).

Sementara itu di Malaysia, bahasa Tamil di sekolah-sekolah dasar diajarkan jika setidaknya ada lima belas orang siswa yang menginginkannya. Di sekolah-sekolah nasional-National Schools- bahasa Melayulah yang digunakan. Di dalam pemerintahan Malaysia, kebijakan tentang bahasa tidak dibuat oleh orang-orang Tamil. Meskipun konstitusi Malaysia memberikan jaminan terhadap penggunaan bahasa Tamil sebagai bahasa resmi (official) tetapi seakan-akan unofficial karena hanya bahasa Melayu yang mungkin digunakan di dalam pemerintahan.

Meskipun peraturan tentang penggunaan bahasa atau pemilihan bahasa dalam dunia pendidikan dan kebijakan Pemerintah Singapura tidak seketat yang terjadi di Malaysia, namun pada kenyataannya di Singapura bahasa Inggris dituturkan oleh sebagian besar masyarakatnya (bahkan sudah menjadi bahasa ibu pada masyarakat generasi baru) dan bahasa lain, seperti bahasa Tamil terdesak. Mereka beranggapan bahwa bahasabahasa seperti bahasa Tamil dan bahasa Cina secara ekonomi tidak menguntungkan/tidak memberi nilai kepada mereka. Terlebih lagi sebagian besar masyarakat Singapura merupakan keturunan Cina atau imigran dari 
Cina yang berkecimpung dalam dunia bisnis, sementara bahasa Tamil banyak digunakan oleh orang-orang yang bekerja di perkebunan atau pekerja perkebunan. Profesi-profesi yang menggunakan bahasa Inggris mendapat tempat yang baik, sehingga orang-orang yang bisa betutur bahasa Inggris dengan baik akan memperoleh pekerjaan yang baik pula.

Sebenarnya gejala-gejala tersebut juga mulai muncul di kota-kota besar di Indonesia, seperti Jakarta dan Surabaya, terlebih-lebih dengan munculnya beberapa perusahaan asing di Indonesia. Tentu saja, perusahaanperusahaan asing tersebut membutuhkan karyawan yang dapat berbicara bahasa Inggris dengan baik, bahkan di tempat bekerja justru bahasa asing, seperti bahasa Inggris menjadi lebih dominan digunakan dibandingkan bahasa Indonesia.

Selain karena faktor ekonomi, faktor sosial, seperti prestige atau kebanggaan menggunakan bahasa tertentu atau secara sosial lebih disukai, dan faktor pendidikan lainnya berpengaruh terhadap pemilihan suatu bahasa/kode yang selanjutnya bisa berakibat pergeseran bahasa di dalam masyarakat yang sebelumnya merupakan masyarakat bilingual atau multilingual.

There is a long history in certain western societies of people actually 'looking down' on those who are bilingual. We give prestige to only a certain few 'classical' languages (e.g., Greek and Latin) or modern languages of 'high' culture (e.g., English., French, Italian, and German). You generally get little credit for speaking Shawili and, until recently at least, not much more for speaking Russian, Japanese, Arabic, or Chinese (Wardhaugh, 1992: 101).

Di Malaysia, beberapa pejabat yang bekerja untuk Menteri Pendidikan secara profesional menyatakan bahwa orang-orang keturunan Tamil tidak mau menyekolahkan anak-anak mereka di sekolah Tamil karena sekolah-sekolah yang menggunakan bahasa Tamil sebagai bahasa pengantar secara profesional/berkaitan dengan profesi dan sosial tidak berfungsi apapun. Di Singapura, sangat sulit menjumpai orang-orang Singapura keturunan Tamil yang terpelajar berkomunikasi dalam bahasa Tamil.

Sikap pemerintah suatu negara terhadap kebijakan bahasa (langauge policy) tampaknya juga sangat berpengaruh terhadap perkembangan suatu bahasa/kelangsungan suatu bahasa. Misalnya di Malaysia, kebijakan tentang bahasa merupakan suatu topik yang secara terbuka tidak boleh didiskusikan karena peraturan yang ada yaitu The Sedition Act of 1948. Kebijakan, seperti yang tercantum dalam Constitution (Amandemnet) Act, 1971, yaitu bahwa status bahasa Melayu adalah sebagai bahasa resmi yang berlaku dan bahasa-bahasa lain diperbolehkan digunakan, tidak perlu lagi dipertanyakan, menganggap masalah tersebut sebagai masalah yang sensitif untuk dibicarakan dan harus di lepaskan dari diskusi publik.' (Suffian bin Hashim dalam Shiffman, 1996). Pembahasan tentang masalah tersebut dikhawatirkan akan mengganggu sensibilitas etnik tertentu di Malaysia. Shiffman (1996) menambahkan bahwa dalam mempertahankan bahasa, Malaysia menekankan pada integrasi lewat Bahasa Malaysia dan Islam. Sementara itu di Singapura kebijakan mengenai bahasa secara terbuka boleh dibicarakan, lebih toleran terhadap bahasa-bahasa yang berkembang disana, seperti bahasa Tamil, dan diberlakukan kebijakan' keseimbangan'/ 'egalitarian' policy (tetapi tampaknya tidak secara penuh mengakui kesamaan hak bagi bahasa-bahasa lain selain bahasa Inggris). Kebijakan-kebijakan yang diberlakukan oleh suatu negara terhadap bahasa yang berkembang di negara tersebut berimbas kepada sistem-sistem lain yang ada di negara tersebut, misalnya pada sistem pendidikan di negara yang bersangkutan, yang telah dijelaskan di bagian sebelumnya dari makalah ini. 


\section{PEM ERTAHA NA N BAHASA (LANGUAGE MAINTENANCE)}

\section{Dampak Pergeseran Bahasa}

Peristiwa pergeseran bahasa bisa saja terjadi di mana-mana karena arus mobilitas penduduk dunia berkembang disamping karena fungsi suatu bahasa dirasa lebih menguntungkan sebagai sarana berkomunikasi/ sarana mencari nafkah maupun sebagai alat integrasi suatu masyarakat/bangsa. Dampak terburuk yang bisa ditimbulkan dari pergeseran bahasa adalah kematian bahasa atau punahnya bahasa (language death/language loss) bahkan bisa menyebabkan kematian budaya masyarakat tertentu. Misalnya yang terjadi pada bahasa Petagonian Welsh di Argentina. Pada tahun 1865, 150 orang Inggris (Welsh) menduduki kota Patagonia di Argentina. Pada tahun 1900an terdapat hampir 3.000 penutur bahasa Patagonia atau yang disebut Patagonian Welsh. Tetapi sekarang bahasa tersebut hilang, dalam arti tidak ada lagi penutur bahasa tersebut dan masyarakat disana menggunakan bahasa Spanyol. Grimes (2000) menambahkan bahwa ada dua akibat lain dari pergeseran bahasa, yaitu rasa ketakutan dan tertekan pada suatu masyarakat yang bahasanya tidak lagi digunakan dan mereka menjadi anti-sosial dan kehilangan rasa percaya diri.

Ada beberapa cara atau gejala yang menunjukkan terjadinya kepunahan atau kematian suatu bahasa, yaitu (1) penutur yang semakin sedikit, (2) domain-domain penggunaan bahasa tersebut yang semakin sedikit, dan (3) terjadi penyederhanaan secara struktural dalam bahasa tersebut (Dorian dalam Kindell, 2000). Sementara itu Krauss (dalam Kindell, 2000) menyebutkan beberapa kategori bahasa, dan salah satunya merupakan ciri dari bahasa yang terancam punah/mati yang sering disebut endangered language. Ketiga kategori bahasa tersebut adalah (1) moribund: bahasa yang tidak lagi dipelajari sebagai bahasa ibu oleh anak-anak, (2) endangered: bahasa yang akan berhenti dipelajari oleh anak-anak dalam kurun waktu yang tidak lama, jika tidak ada upaya pemertahanan, dan (3) safe: bahasa yang mendapat dukungan dari negara/ sebagai bahasa resmi dan digunakan secara luas oleh penuturnya.

Tidak bisa dihindari, salah satunya sebagai konsekuensi dari semakin berkembangnya mobilitas masyarakat dunia ke berbagai daerah atau negara dengan berbagai motivasi, munculnya pergeseran bahasa bahkan kematian bahasa, yang juga akan berakibat hilangnya budaya suatu masyarakat tertentu. Namun demikian kematian bahasa bisa dicegah dengan upaya-upaya pemertahanan bahasa (language maintenance).

\section{Pemertahanan Bahasa melalui Sikap Bahasa}

Ketika berbicara tentang pemertahanan bahasa, kita tidak bisa lepas dari sikap terhadap bahasa atau sikap bahasa (language attitude). Sudah dijelaskan pada bagian lain dalam makalah ini bahwa sikap bahasa mencakup sikap, keyakinan seseorang (kelompok) dalam memandang suatu bahasa (baik terhadap bahasa itu sendiri maupun penutur bahasa tersebut) yang berpengaruh pada reaksinya. Sikap tersebut bisa positif atau negatif. Pada suatu negara sikap pemertahanan bahasa tidak hanya mencakup sikap seseorang/individu terhadap bahasa, tetapi juga mencakup sikap masyarakat secara umum, pemerintah, para ahli/ peneliti bahasa, dan masyarakat dunia. Bisa diasumsikan bahwa suatu bahasa yang digunakan/dimiliki oleh sekelompok masyarakat pendatang dapat dipertahankan sebagai alat komunikasi jika kelompok tersebut memiliki sikap positif terhadap bahasanya atau masyarakat yang didatangi memberikan sikap positif dalam arti memberikan nilai positif atau keuntungan bagi mereka, jika tidak maka kemungkinan besar bahasa para pendatang tersebut akan hilang dengan cepat. Heye (dalam McCormark dan Wurm, 1979: 414) menyatakan:

Language attitudes are taken to be those feelings and subjective manifestations which the individual has towards his own native language as

Pergeseran Bahasa (Dwiyani Pratiwi) 
well as towards other contact languages. .....In cases of immigrant and national language contacts, questions of language attitudes are often intimaly related to questions of language maintenance, i.e. the subjective values atrributed to one will influence the direction and extent of use of the other.

Garvin dan Mathiot dalam Chaer dan Agustina (1995: 201) mengatakan bahwa sikap positif yang diperlukan untuk mempertahankan suatu bahasa mencakup: (1) kesetiaan bahasa (language loyalty), (2) kebanggaan bahasa (language pride), dan (3) kesadaran adanya norma bahasa (awarness of the norm). Masyarakat desa Lolon di Bali yang beragama Islam dapat mempertahankan keberadaan bahasanya, bahasa Melayu Lolon (asal usul penuturnya adalah masyarakat dari Bugis dan Pontianak) ditengah-tengah masyarakat Bali yang berbahasa Bali yang lebih dominan. Faktor-faktor yang dapat menyebabkan mereka dapat mempertahankan bahasa mereka adalah (1) wilayah pemukiman mereka terkonsentrasi pada suatu tempat yang secara geografis agak terpisah dari pemukiman masyarakat Bali, (2) toleransi dari masyarakat mayoritas Bali yang mau menggunakan bahasa Melayu Loloan dalam berinteraksi itu kadang-kadang digunakan juga bahasa Bali, (3) anggota masyarakat Loloan mempunyai sikap keislaman yang tidak akomodatif terhadap masyarakat, budaya, dan bahasa Bali dan terkonsentrasinya masyarakat Loloan menyebabkan minimnya interaksi fisik antara masyarakat Loloan (minoritas) dan Bali (mayoritas) sehingga tidak digunakannya bahasa Bali dalam interaksi intra kelompok, (4) loyalitas yang tinggi dari anggota masyarkat Loloan terhadap bahasa Melayu Loloan, sebagai konsekuensi kedudukan atau status bahasa Melayu Loloan sebagai identitas diri masyarakat Loloan yang beragama Islam dan penggunaan bahasa Bali ditolak terutama interaksi yang berkaitan dengan ranah agama, dan (5) kesinambungan pengalihan bahasa
Melayu Loloan dari generasi terdahulu ke generasi berikutnya. (Sumarsono dalam Chaer dan Agustina, 1995).

Masyarakat Tamil yang minoritas dan berbahasa Tamil (terdapat masyarakat Tamil yang berpendidikan yang tidak lagi menggunakan bahasa Tamil) melalui sistem pendidikan yang diterapkan oleh pemerintah Malaysia dapat mempertahankan keberadaan bahasa Tamil meskipun penggunaannya tidak luas. Strategi-strategi yang diterapkan dan dipertahankan oleh masyarakat Tamil yaitu: (1) pada sekolah dasar tetap digunakan bahasa Tamil, (2) bahasa Inggris digunakan pada sekolah-sekolah pada level yang lebih tinggi dan cukup berguna pada lingkungan yang baru, dan (3) bahasa-bahasa lokal lainnya yang perlu atau berguna digunakan sebagai alat bantu bukan sebagai bahasa yang mendapat prioritas pertama atau kedua. Selain itu meskipun minoritas masyarakat Tamil yang kurang terpelajar dan tinggal di komunitas perkebunan tetap berbahasa Tamil.

Sikap pemerintah terhadap bahasa memberikan kontribusi sangat besar pada kelangsungan suatu bahasa, yaitu bagaimana pemerintah merencanakan program-program dalam mempertahankan bahasa, baik bahasa penduduk asli maupun pendatang. Pada awal tahun 1900 penduduk Hawai yang bisa berbahasa Hawai hanya berjumlah 37.000 bahkan sekarang diperkirakan hanya ada sekitar 1000 penduduk Hawai yang bisa berbahasa Hawai, dimana pada pertengahan abad 18 penutur bahasa Hawai berjumlah 500.000. Beberapa faktor menjadi penyebab hampir punahnya bahasa Hawai. Diantaranya adalah dikuasainya perekonomian Hawai oleh para pebisnis dari Amerika pada tahun 1893. Hal tersebut menyebabkan Bahasa Inggris menjadi bahasa nasional dan diharapkan untuk tidak menggunakan bahasa Hawai baik di sekolah maupun di rumah. Keadaan tersebut berlanjut terus, terlebih lagi ketika Amerika menjajah Hawai pada tahun 1898. Akan tetapi keberadaan bahasa Hawai bisa dipertahankan sampai sekarang karena adanya sikap positif pemerintahan yang ada di Hawai dan 
masyarakat Hawai sendiri untuk mempertahankan bahasa Hawai dengan melaksanakan berbagai program di bidang pendidikan. Mereka mulai membangun 'total immersion school', dan telah memiliki kelas mulai level satu sampai duabelas yang menggunakan bahasa Hawaii, bahkan sekolah ini diikuti juga oleh para orang tua yang ingin bisa berbicara dengan bahasa Hawai dengan anak-anak mereka di rumah (Grimes, 2000).

Sikap terhadap suatu bahasa tidak hanya mencakup suatu bahasa secara menyeluruh tetapi bisa mencakup variasi bahasa, kata, frase, dan kalimat bahkan pengucapan dan aksen. Meskipun keduanya adalah bahasa Inggris, masing-masing bahasa Inggris Amerika (American English) dan bahasa Inggris yang diucapkan oleh orang Inggris (British English) disikapi berbeda oleh masing-masing penuturnya. Misalnya, orang Amerika terutama dari New York menghilangkan bunyi ' $r$ ' dalam mengucapkan kata-kata tertentu seperti sugar (shuguh) atau never (nevuh). Oleh orang Inggris (dalam British English) penghilangan bunyi ' $\mathrm{r}$ ' dianggap vulgar, tidak elegan, dan termasuk ucapan masyarakat kelas bawah. Bahkan sikap negatif terhadap suatu bahasa tertentu bisa terkait dengan penutur bahasa itu sendiri dan penilaian terhadap kemampuan atau intelegensi seseorang. Giles dan Coupland dalam Thomas, et al (2004:207) memaparkan hasil sebuah penelitian yang menyebutkan bahwa sikap negatif terhadap suatu bahasa dan penuturnya sudah menyentuh lingkungan pendidikan paling bawah yaitu kelas. Persepsi guru terhadap bahasa yang digunakan oleh siswanya mempengaruhi penilaian guru terhadap kemampuan akademis siswanya.

Jika sikap-sikap atau perlakuanperlakuan negatif terhadap bahasa dan individu atau kelompok penuturnya terus berlangsung dan salah satu bahasa atau variasi bahasa mendominasi atau lebih menguntungkan maka akan muncul rasa malu, rendah diri, dan takut untuk menggunakan suatu bahasa atau dialek. Giles dan Coupland juga menyarankan perlunya sikap positif terhadap bahasa dan penuturnya. Sebagai contoh ketika bertemu dengan seseorang dengan bahasa atau aksen yang berbeda kita bisa meresponnya secara positif, antaralain dengan cara mendengarkan ucapannya, berusaha menyesuaikan kebiasan berbahasa kita dengan kebiasaan berbahasanya, menyesuaikan gaya bicara dengan gaya bicara orang lain, merespon dengan sopan, dan sebagainya. Sikap-sikap tersebut akan menciptakan kesan yang positif pada kedua penutur.

\section{E. SIMPULAN}

Kontak bahasa sebagai alat untuk berkomunikasi tentu saja tidak bisa dihindari. Sementara itu kontak bahasa pada masyarakat bilingual maupun multilingual dapat memberikan dampak, antaralain interferensi, integrasi, perubahan bahasa (language change), pergeseran bahasa (language shift), dan kematian bahasa (language death).

Pergeseran bahasa bisa disebabkan oleh beberapa faktor, yaitu migrasi penduduk, perkawinan, prestis, ekonomi, pendidikan, kebijakan pemerintah, dan bencana alam. Pergeseran bahasa terjadi melalui proses yang cukup lama. Pada masyarakat imigran proses ini mencakup beberapa tahap mulai dari perubahan masyarakat pendatang menjadi masyarakat bilingual (menggunakan bahasa masyarakat yang didatangi) sampai pada tahap tidak lagi digunakannya bahasa ibu mereka. Hal yang paling mengkhawatirkan dari proses pergeseran bahasa ini adalah tidak lagi digunakannya bahasa ibu oleh penuturnya yang bisa menyebabkan hilangnya atau matinya bahasa (ibu), bahkan kematian budaya mereka.

Namun demikian, kematian atau punahnya suatu bahasa dan budaya pada masyarakat tertentu bisa dicegah melalui sikapsikap yang diupayakan untuk kelangsungan suatu bahasa. Sikap-sikap positif dalam pemertahanan suatu bahasa tidak hanya datang dari pemerintah, masyarakat secara umum, para peneliti dan ahli bahasa, tetapi juga dari individu penutur bahasa tersebut untuk tetap mempertahankan bahasa mereka sebagai bagian dari kebudayaan yang mereka dan nenek 
moyang mereka miliki. Sikap positif terhadap suatu bahasa juga bisa datang dari penutur bahasa lain, seperti sikap saling menghargai antar penutur bahasa yang berbeda, dan menganggap bahasa adalah suatu bagian dari budaya sekelompok masyarakat tertentu.

\section{DAFTAR PUSTAKA}

Chaer, A. dan Agustina, L. 1995. Sosiolinguistik: Perkenalan Awal. Jakarta: PT Rineka Cipta.

Crystal, D. 1987. The Cambridge Encyclopedia of Language. Cambridge: CUP.

Edwards, J. 1994. Multilingualism. London: Penguin Books.

Grimes, B.F. 2000. "Global Language Visbility: Causes, Symton and Cures for Endangered Languages." http://www.sil.org/sociolx/ndg-lggrimes.html.

Holmes, J. (6 $6^{\text {th }}$ ed.) 1995. An Introduction to Sociolinguistics. London: Longman.

Kindell, G. 2000. "Endangered Language Group." http://www.sil.org/ sociolx/ndg-lg-grps.html

McCormack, W.C. and Wurm, S.A. 1979. Language and Society: Anthropological Issues. Paris: Mouton Publishers.

Richards, J., Platt, J., dan Weber, H. 1985. Longman Dictionary of Applied Linguistics. Essex: Longman.

Schiffman, H.F. 1996. "Language Shift in the Tamil Communities of Malaysia and Singapore: the Paradox of Egalitarian $\mathrm{L}$ a $\mathrm{n} \mathrm{g}$ u a $\mathrm{g}$ e $\mathrm{P}$ o $1 \mathrm{i} \mathrm{c} \mathrm{y}$. " http://ccat.sas.upenn.edu/ harolds/54 0/handouts/sparadox/sparadox.html.

Thomas, L. et al. ( $2^{\text {nd }}$ ed.) 2004. Language, Society, and Power. London: Routlegde.

Wardhaugh, R. ( $2^{\text {nd }}$ ed.) 1992. An Introduction to Sociolonguistics. Cambridge: Blackwell Publishers. 